\title{
Basal secretion and anaphylactic release of rat mast cell protease-II (RMCP-II) from ex vivo perfused rat jejunum: translocation of RMCP-II into the gut lumen and its relation to mucosal histology
}

\author{
C L Scudamore, A M Pennington, E Thornton, L McMillan, G F J Newlands, \\ H R P Miller
}

\begin{abstract}
The kinetics of the release of rat mast cell protease-II (RMCP-II) from mucosal mast cells in the jejunum of Nippostrongylus brasiliensis primed (immune) rats was investigated using ex vivo perfusion of a segment of jejunum through the cranial mesenteric artery. The aim of the study was to assess the role of the protease in anaphylaxis and in particular to ascertain whether it is responsible for the histological changes, which include widespread epithelial shedding, seen in the mucosa in in vivo models of anaphylaxis. Perfusion of the jejunal vasculature with a KrebsRinger buffer showed that there was basal secretion of RMCP-II by jejunal mast cells in all rats studied. The baseline concentration of RMCP-II was significantly greater $(p<0.05)$ in immune rats $(>7$ ng/ml) previously exposed to nippostrongylus infection than in control, naive animals ( $<2 \mathrm{ng} / \mathrm{ml})$. Challenge of immune rats with 100 or 400 worm equivalents of whole worm antigen resulted in an immediate (within 40 seconds) and significant $(p<0.02)$ increase in the concentration of RMCP-II (to $>3 \mu \mathrm{g} / \mathrm{ml}$ ) in the vascular perfusate, which was not seen in naive rats or immune rats challenged with an irrelevant antigen. Greater amounts of RMCP-II were also recovered from the jejunal lumen of immune rats compared with naive rats after challenge of both groups with worm antigen. Despite the release of microgram quantities of RMCP-II into the gut lumen and vascular perfusate, however, there were no significant changes seen in the mucosal histology. These results suggest that RMCP-II alone is not responsible for the loss of gut epithelium seen during anaphylaxis in the rat.

(Gut 1995; 37: 235-241)
\end{abstract}

Keywords: mast cell protease, chymase, anaphylaxis, RMCP-II, ex vivo perfusion.

The participation of mucosal mast cells in a range of inflammatory intestinal diseases and food hypersensitivity in humans ${ }^{12}$ and the immune rejection of nematode parasites in animals ${ }^{3}$ is well established. A wide variety of preformed (histamine, proteoglycans, proteases) and newly synthesised mediators (platelet activating factor, leukotrienes, prostaglandin) are released from mucosal mast cells during disease processes and many studies have attempted to define the functional significance of the release of individual mediators. The comparative importance of specific mediators in the establishment of mucosal pathology and permeability, however, has not been established and in particular the role of the neutral serine proteases has been neglected.

Systemic anaphylaxis in rats sensitised by nematode infection and challenged with worm antigen results in severe damage to the gut mucosa and it is thought that mucosal mast cells play a part in this process. A highly soluble mast cell granule chymase, rat mast cell protease-II (RMCP-II), predominantly found at mucosal surfaces, is abundant in normal rat intestine $(300 \mu \mathrm{g} / \mathrm{g}$ wet weight) and concentrations are increased five- to 10 fold after infection with nematode parasites. ${ }^{4}$ RMCP-II is released systemically during expulsion of Nippostrongylus brasiliensis and into the gut lumen and vasculature during anaphylaxis. ${ }^{56}$ Type IV collagen is a possible substrate for RMCP-II ${ }^{7}$ and it has been hypothesised that damage to collagen in the basement membrane results in shedding of epithelial cells in the jejunum, which is seen during anaphylaxis ${ }^{6}$ or in increased mucosal permeability during worm expulsion. ${ }^{38}$ These changes may be beneficial in the removal of parasites from the mammalian gut by allowing plasma proteins, cytokines, and specific antibodies to come into direct contact with the parasite, causing damage or death of the worms and thereby aiding expulsion. ${ }^{9}$ There may also be disadvantages, however, in allowing food and bacterial antigens to be more readily taken up from the gut lumen into the systemic circulation. ${ }^{10}$

The aim of this study was to use an ex vivo perfusion model to monitor the timing and magnitude of RMCP-II secretion by mucosal mast cells in the jejunum before and after worm antigen induced anaphylaxis and to assess the relation of protease release to histological changes. 


\section{Methods}

EX VIVO PERFUSION MODEL

The perfusion system used was a modification of that devised by Hanson and Parsons ${ }^{11}$ as described by Pennington, ${ }^{12}$ where viability was established by measurement of glucose uptake. Briefly, outbred male Wistar rats (mean weight $340 \mathrm{~g}$ ) (Bantam and Kingman Universal, Hull, UK) were anaesthetised with $84 \mathrm{mg} / \mathrm{kg}$ pentobarbitone sodium (Sagatal, Rhône Merieux) and the vasculature of a $34.4(1.3) \mathrm{cm}$ (mean (SEM)) length of jejunum (starting $5 \mathrm{~cm}$ distal to the ligament of Treitz) was isolated by ligating the blood vessels supplying the spleen, rectum, colon, stomach, and ileum. The cranial mesenteric artery (perfusate inflow) and hepatic portal vein (perfusate outflow) were cannulated. The vasculature was immediately perfused, at a rate of roughly $1.5 \mathrm{ml} / \mathrm{min}$, with Krebs-Ringer buffer (pH 7.4) containing $5 \mathrm{mM}$ glucose and, to maintain oncotic pressure and increase oxygen carrying capacity, $10 \% \mathrm{w} / \mathrm{v}$ Ficoll 70 (Sigma Chemical), which was continuously gassed with $95 \% \mathrm{O}_{2} / 5 \% \mathrm{CO}_{2}$ and maintained at $37^{\circ} \mathrm{C}$. The perfusion was a one way system with no recirculation of media through the vasculature. Timing for sample collection (zero time point) started when continuous, blood free outflow was established from the hepatic portal vein cannula, usually less than two minutes after the actual start of perfusion. Samples of the perfusate outflow were collected at intervals as described later. Vascular perfusion was terminated after 31 minutes and the lumen of the perfused gut was flushed out with $50 \mathrm{ml}$ isotonic saline and the effluent stored at $-70^{\circ} \mathrm{C}$.

\section{INFECTION WITH NIPPOSTRONGYLUS} BRASILIENSIS

The methods used to maintain the nematode Nippostrongylus brasiliensis, to harvest third stage larvae (L3) and to infect rats have been described previously. ${ }^{13}$ Soluble worm antigen

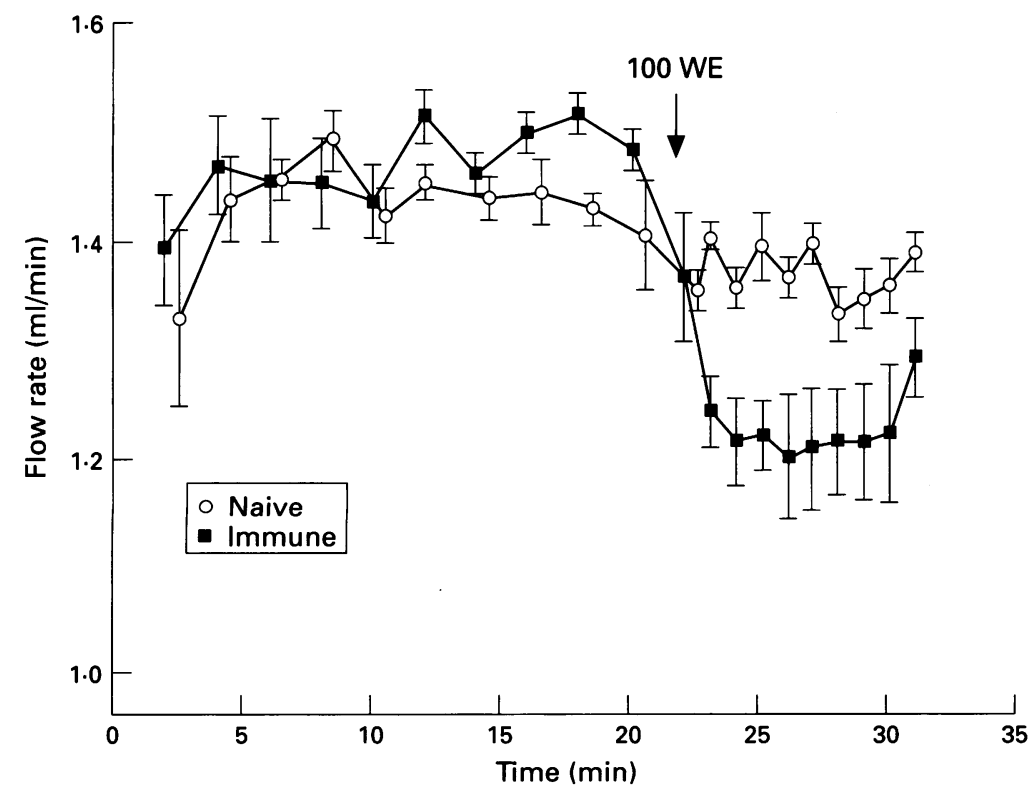

Figure 1: Effect of intravascular challenge with 100 worm equivalents (WE) of worm antigen on vascular perfusate outflow rate (mean (SEM)). was prepared from adult Nippostrongylus brasiliensis harvested from the small intestine of infected rats. ${ }^{14}$ The worms were counted and homogenised in a known volume of KrebsRinger buffer and centrifuged at $12000 \times g$ for 30 minutes. The supernatant was diluted with Krebs-Ringer to give a final concentration equivalent to 100 or 400 worms in $0.1 \mathrm{ml}$ (worm equivalents).

\section{EXPERIMENTAL DESIGN AND SAMPLE \\ COLLECTION}

Three groups of rats were used in the course of the experiments. Immune rats (an immune control and a worm antigen challenged immune group) were infected four weeks and one week before perfusion with 3000 Nippostrongylus brasiliensis L3 injected subcutaneously. The third group comprised uninfected controls (naive).

Naive and immune rat preparations were challenged with 100 (experiment 1; $n=5$ /group) or 400 (experiment $2 ; n=4$ naive group, $\mathrm{n}=5$ immune group) worm equivalents of worm antigen. In experiment 2 an immune control group $(n=4)$ received a challenge bolus of protein (bovine serum albumin) equal to the total protein concentration $(5.4 \mathrm{mg} / \mathrm{ml})$ of 400 worm equivalents.

For the first 20 minutes, samples were collected for one minute intervals every second minute (that is, $10 \times 1$ minute samples). Worm antigen and protein challenges were given as a $0.1 \mathrm{ml}$ bolus into the perfusion inflow at 21 minutes 50 seconds after the start of perfusion. For the following 10 minutes (starting at 22 minutes) samples were collected for 30 seconds at one minute intervals (that is, $10 \times 30$ second samples).

\section{HISTOLOGICAL ANALYSIS}

At the end of each perfusion a $10 \mathrm{~cm}$ section of proximal jejunum was fixed in $4 \%$ paraformaldehyde in phosphate buffered saline. The tissue was then embedded in paraffin wax and $4 \mu \mathrm{m}$ sections were processed and stained with haematoxylin and eosin. Stained sections were examined microscopically and lesions were scored on a scale of $0-5$ (where $0=$ no lesions, $5=$ extensive lesions). Scoring was done blind by one observer and entailed estimating the proportion and extent of lesions in 50 or more villi using longitudinal sections of gut where sectioned villi have a finger like appearance rather than the spatulate shape seen in transverse sections. ${ }^{4-6}$

MEASUREMENT OF PERFUSATE AND TISSUE RMCP-II CONCENTRATIONS

Two to three cm sections of jejunum were weighed and stored at $-70^{\circ} \mathrm{C}$ immediately after perfusion. They were homogenised on ice, centrifuged at $8000 \times g$ for 30 minutes, and the supernatant retained for analysis. RMCPII concentrations in vascular perfusate, gut lumen flushes, and the supernatants from tissue homogenates were analysed by enzyme 

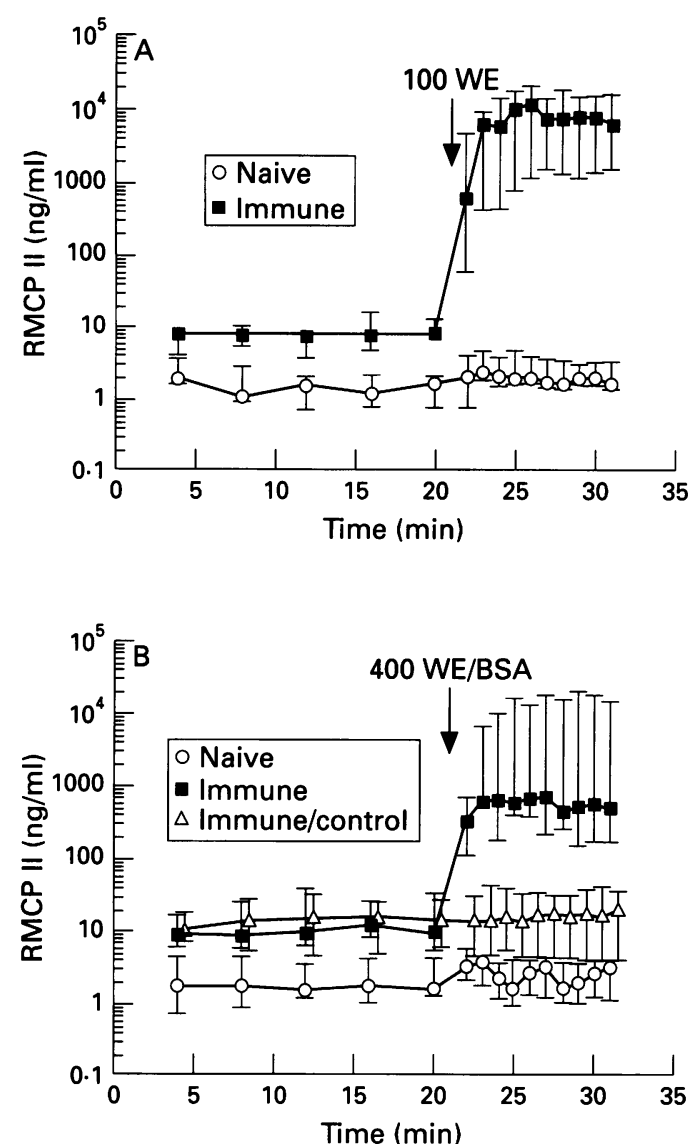

Figure 2: RMCP-II concentration (median and range) in the vascular perfusate outflow before and after intravascular challenge with $100(A)$ or $400(B)$ worm equivalents (WE) of worm antigen or bovine serum albumin (B).

linked immunosorbent assay (ELISA) as previously described ${ }^{4}$ apart from the use of 3,3',5,5'-tetramethylbenzidine (Kirkegaard and Perry Laboratories, Gaithersburg, USA) as the substrate.

\section{STATISTICAL ANALYSES}

One way analysis of variance and unpaired Student's $t$ test were used to compare flow rate data. As data obtained in this experiment for RMCP-II concentrations were not normally distributed the non-parametric Kruskal-Wallis and Mann-Whitney tests were used as appropriate for analyses. A significance value of $\mathrm{p}<0.05$ was used throughout. Analyses were performed using Minitab software. RMCP-II concentration data in text, Figures, and the Table are presented as medians (range) unless otherwise stated and flow rate data are presented as mean (SEM) values.

Scores obtained for histological features of sections taken from perfused jejunum median (range)

\begin{tabular}{lllllll}
\hline & $\begin{array}{l}\text { Treatment } \\
\text { group }\end{array}$ & No & $\begin{array}{l}\text { Epithelial } \\
\text { shedding } \\
\text { at tips of villi }\end{array}$ & $\begin{array}{l}\text { Blebbing } \\
\text { of epithelia } \\
\text { at sides of villi }\end{array}$ & $\begin{array}{l}\text { Crypt } \\
\text { necrosis }\end{array}$ & $\begin{array}{l}\text { Oedema } \\
\text { of lamina } \\
\text { propria }\end{array}$ \\
\hline Experiment 1 & Naive & 5 & $1(0-3)$ & $0(0-2)$ & $0(0-1)$ & $0(0-1)$ \\
& Immune & 5 & $2(1-3)$ & $0(0-0)$ & $3(0-5)$ & $0(0-0)$ \\
Experiment 2 & $\begin{array}{l}\text { Naive } \\
\text { Immune }\end{array}$ & 4 & $2(1-3)$ & $1 \cdot 5(0-2)$ & $0(0-0)$ & $1(1-2)$ \\
& $\begin{array}{l}\text { Immune/ } \\
\text { control }\end{array}$ & 4 & $1 \cdot 5(1-2)$ & $1(1-3)$ & $0(0-1)$ & $1(0-2 \cdot 5)$ \\
& & & $1(0-2)$ & $0(0-2)$ \\
\hline
\end{tabular}

$0=$ no lesion, $5=$ extensive lesions.

No significant differences were noted in lesion scores between treatment groups.

\section{Results}

\section{VASCULAR PERFUSATE}

\section{Flow rate}

Experiment 1 - perfusate outflow rate for both groups remained constant and the rate was not significantly different when compared between groups during the first 20 minutes of perfusion (Fig 1). In immune rats, outflow rate decreased significantly within 70 seconds of injection of 100 worm equivalents of worm antigen, when compared with the rate for the same group during the basal period $(p<0.001)$. In naive animals there was a tendency to a reduction in flow rate after challenge but this did not reach statistical significance. Comparison between the two groups at each time point, however, showed that the flow rate was significantly $(p<0.05)$ lower in the immune compared with naive rats from 70 seconds after challenge and remained so for a further four minutes.

Experiment 2 - as was shown in the first experiment the flow rate during the first 20 minutes of perfusion was constant and similar for all treatment groups (data not shown). After challenge with 400 worm equivalents of worm antigen both naive and immune rats showed a significant decline in flow rate, which was greater in the immune $(p<0.001)$ than naive rats $(p \leqslant 0 \cdot 05)$. No change in flow rate was seen in the immune control group after challenge with bovine serum albumin. When comparing the difference between the groups, however, the flow rate in the immune group was significantly $(p<0.05)$ lower than both the control groups only at 27,28 , and 31 minutes after the start of the experiment.

\section{Baseline RMCP-II}

Experiment 1 - RMCP-II was released into the vascular perfusate at a basal concentration from all rats during the initial 20 minutes of the perfusion (Fig 2A) (overall mean RMCP-II concentration $1.64 v 7.81 \mathrm{ng} / \mathrm{ml}$ for naive $v$ immune). When comparisons were made at each time point in the first 20 minutes the concentrations of RMCP-II in the perfusate were significantly greater in immune compared with naive rats $(\mathrm{p} \leqslant 0.02)$.

Experiment 2 - as in the first experiment, RMCP-II concentrations in the vascular perfusate were significantly higher $(p<0.05)$ in the immune (including immune control) rats compared with naive rats at every time point during the first 20 minutes of perfusion (Fig 2B) (overall means $1.91 v 11.04 v 12.86 \mathrm{ng} / \mathrm{ml}$ for naive $v$ immune $v$ immune control). RMCP-II concentrations in the perfusates from the two immune groups were not significantly different (Fig 2B).

\section{RMCP-II release}

Experiment 1 - after infusion of 100 worm equivalents of worm antigen the output of RMCP-II was significantly increased in immune animals, when compared with the 


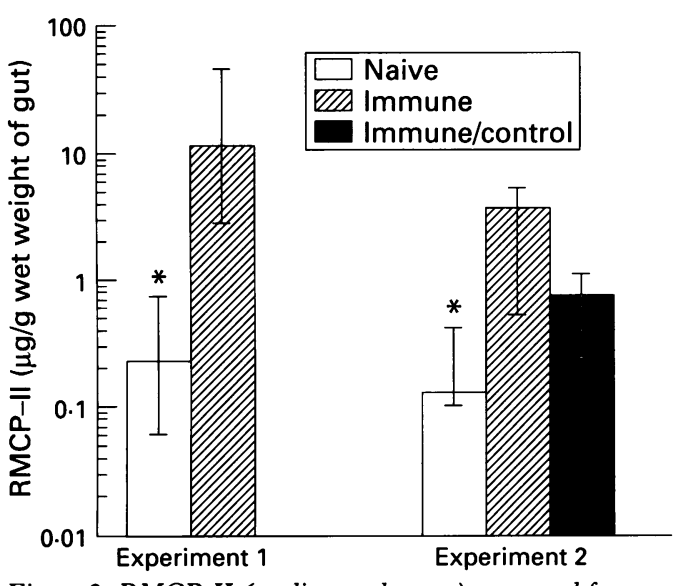

Figure 3: RMCP-II (median and range) recovered from the perfused jejunal lumen expressed as $\mathrm{ng} / \mathrm{g}$ wet weight of jejunum. ${ }^{\star}$ Naive significantly different from immune group (experiment $1 p<0 \cdot 01$, experiment $2 p<0 \cdot 02$ ).

basal concentrations for the same group $(p=0.015)$, from the first post-challenge sample (collected 10-40 seconds after challenge) until the end of the experiment 10 minutes later (Fig 2A). In naive animals there was no change in RMCP-II output after challenge and the concentration was therefore significantly less than in the immune group $(p \leqslant 0.02)$ at each time point in the postchallenge period (overall post-challenge mean $2.22 v 6989 \mathrm{ng} / \mathrm{ml}$ for naive $v$ immune) (Fig 2A).

Experiment 2 - after infusion of 400 worm equivalents of worm antigen there was an immediately (10-40 seconds after challenge) measurable and significant increase in the release of RMCP-II in the immune rats when compared with the basal values in this group $(p=0.007)$, which persisted until the end of the experiment (Fig 2B). In neither control group was any difference seen in the output of RMCPII after challenge with worm antigen or bovine

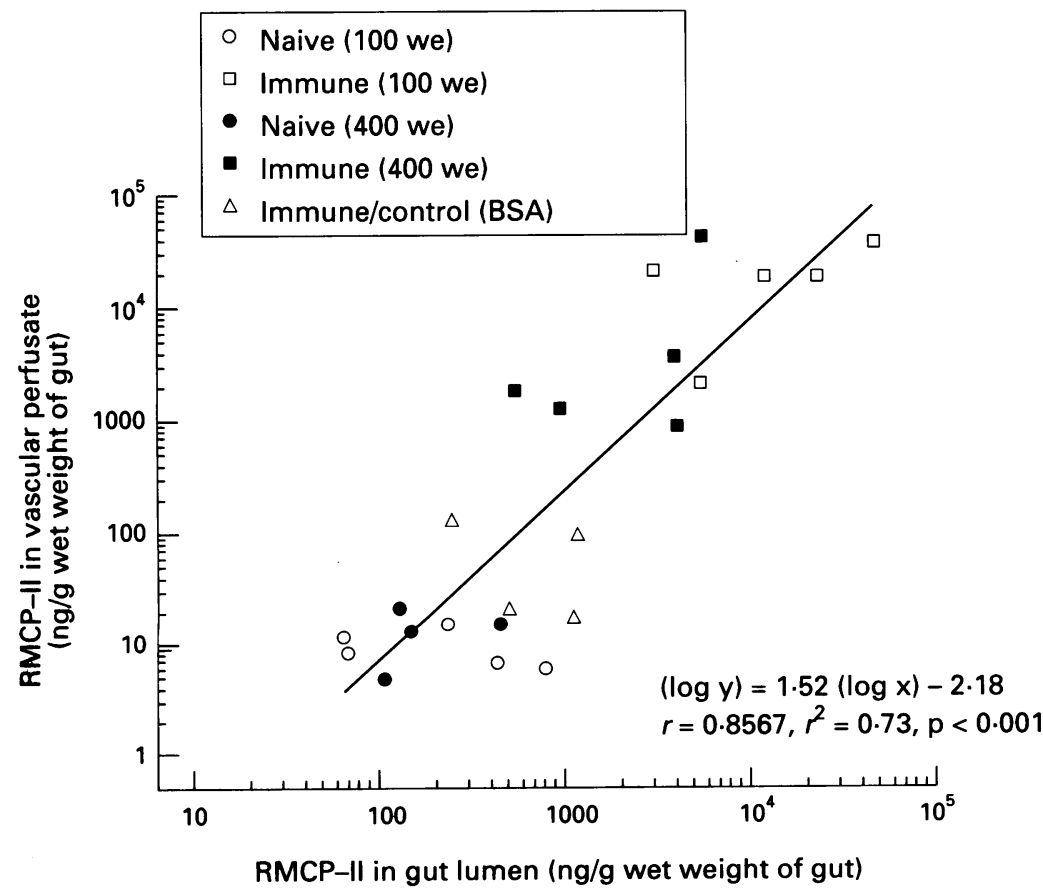

Figure 4: Correlation between the total output of RMCP-II into the vascular perfusate and jejunal lumen (expressed as $\mathrm{ng} / \mathrm{g}$ wet weight of tissue), data pooled from both experiments. serum albumin respectively when compared with baseline values of secretion. Thus at each post-challenge time point, RMCP-II output from the naive and immune control groups remained significantly different from that seen before challenge $(p<0 \cdot 05)$. Significantly more RMCP-II was measured, however, in the perfusates from the immune animals challenged with worm antigen compared with both the other two groups (immune $v$ immune control $\mathrm{p}<0.02$; immune $v$ naive $\mathrm{p}<0.02$ ) (overall postchallenge means 2787 v 15.52 v $2.36 \mathrm{ng} / \mathrm{ml}$ immune $v$ immune control $v$ naive).

\section{GUT LUMEN}

At the end of each perfusion the lumen of the perfused segment of intestine was flushed with $50 \mathrm{ml}$ of saline and the concentration of RMCP-II assessed by ELISA. RMCP-II values were expressed per gram wet weight of perfused intestine to minimise the effect of variation in the length of gut perfused. Analyses showed that RMCP-II was present in the gut lumen of rats from all groups (Fig 3). Significantly more total RMCP-II was measured in the lumen of immune challenged compared with naive rats (immune challenge $v$ naive: experiment $1-11.9 v 0.2(\mathrm{p}<0.01)$; experiment $2-3.8 v 0.1 \mu \mathrm{g} / \mathrm{g}$ wet weight $(p<0.02))$ but the difference between the immune challenge and immune control (immune challenge $v$ immune control $3.8 v$ $0.8 \mu \mathrm{g} / \mathrm{g}$ wet weight) animals in experiment 2 was not significant.

After pooling the data from both experiments, comparison of the amount of RMCP-II released/gram wet weight into the vasculature versus gut lumen showed a significant correlation (Fig 4) $\left(r^{2}=0.72, \mathrm{p}<0.001\right)$ suggesting that the RMCP-II accumulating in the gut lumen was proportional to the amount released into the vasculature.

\section{TISSUE HOMOGENATES}

In experiment 1 the concentration of RMCP-II in the jejunum (Fig 5A) was found to be significantly higher in the immune rats (624 (548-671) $\mu \mathrm{g} / \mathrm{g}$ wet weight) than the naive

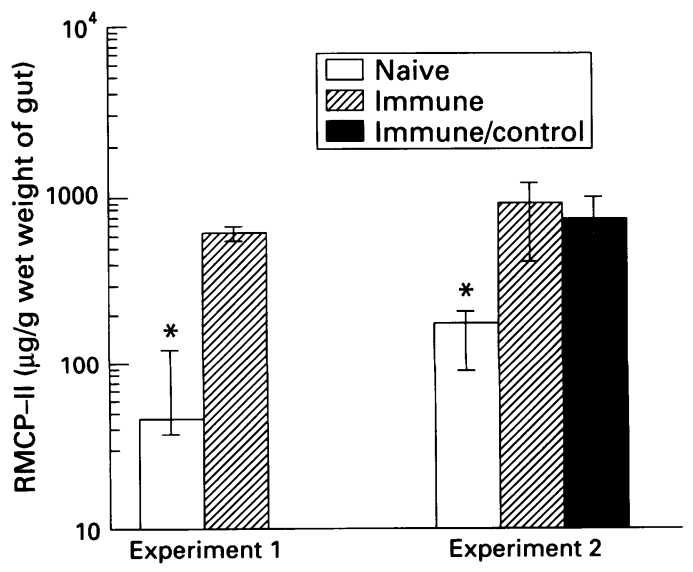

Figure 5: RMCP-II (median and range) extracted from tissue homogenates expressed as $n g / g$ wet weight of jejunum homogenised. *Naive significantly different from other groups (experiment $1 p<0 \cdot 01$, experiment $2 p<0.05$ ). 

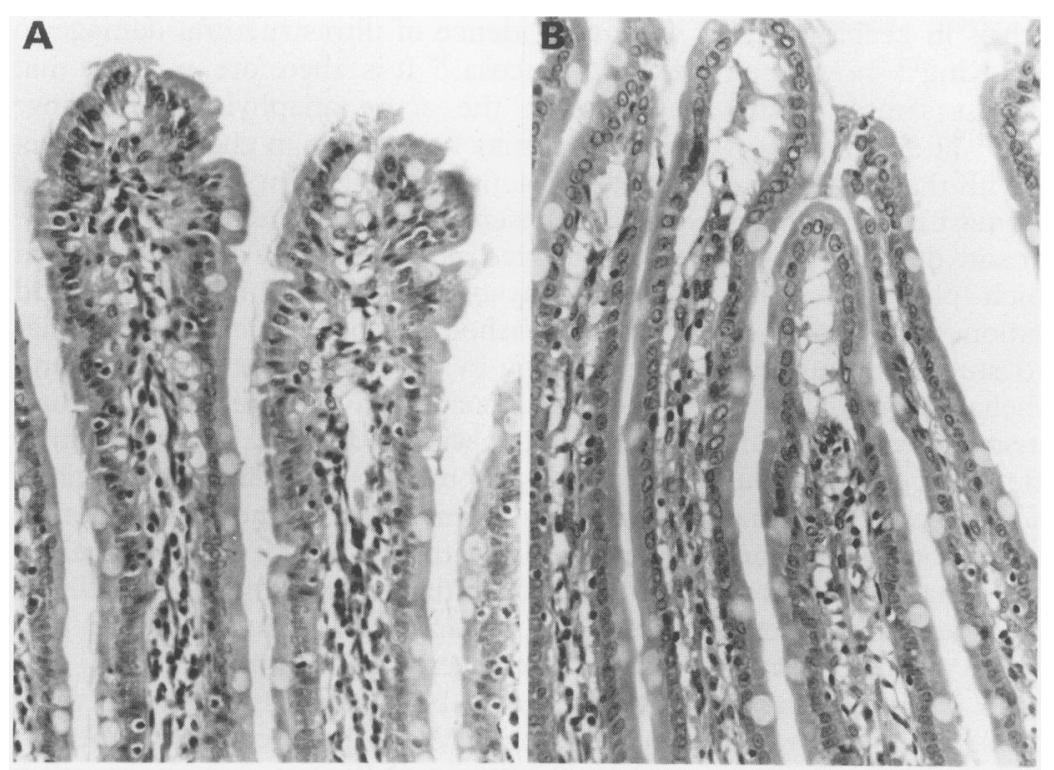

\section{c}
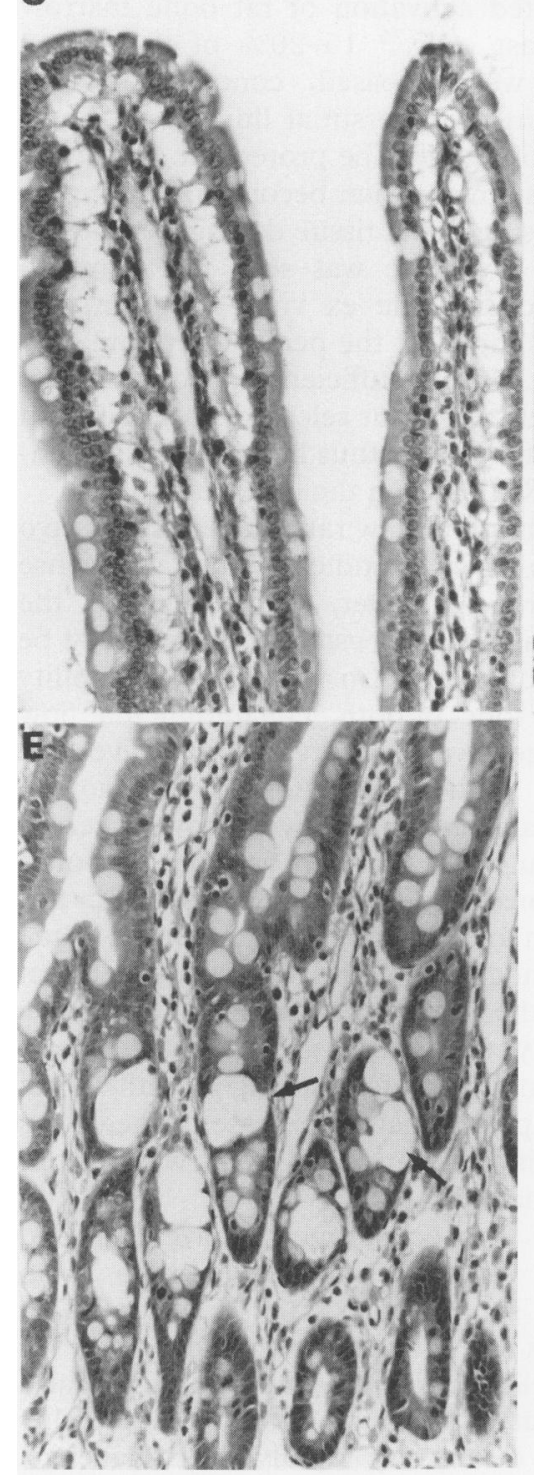

when compared with the naive rats

$(182$ $(93-208))(\mathrm{p}<0 \cdot 05)$.

\section{HISTOLOGICAL ASSESSMENT}

Lesions were quantified in the context of other published data where intact epithelium was separated from the villus tip ${ }^{8}$ or from the sides of villi (blebbing), ${ }^{15}$ or where villous oedema has occurred. Separation of the epithelium from the villus with associated shedding of sheets of epithelial cells into the lumen of the villus and focal degeneration and necrosis of the crypt epithelium were also scored. Figure 6 illustrates these changes.

The Table shows the extent of each lesion. Epithelial shedding from the tips of the villi was noted in some sections from all treatment groups without any obviously increased damage in the immune challenge groups, nor was there any trend when epithelial blebbing or oedema of the lamina propria were considered. Focal lesions in the crypts were more obvious in some of the immune rats than in naive controls but this trend was not statistically significant.

\section{Discussion}

Since its identification and localisation to mucosal mast cells, ${ }^{1617}$ RMCP-II has been used as a marker to quantify the in vivo and in vitro activation and degranulation of this population of cells, ${ }^{518}$ but its physiological/pathological role is still unclear. While the presence of substantial quantities of this protease in normal rat intestine has been described 41619 this study is the first to show the basal secretion of RMCP-II by jejunal mast cells into the local vasculature and gut lumen in normal unparasitised rats. Baseline serum RMCP-II concentrations have previously been reported as $75-200 \mathrm{ng} / \mathrm{ml}^{9}$ in normal rats, 100 times the concentrations seen in this study. This difference may be due to the contribution of mast cells in other parts of the intestine ${ }^{20}$ and to the recirculation of uncleared proteaseserine protease inhibitor complexes. ${ }^{20}$ Basal concentrations of RMCP-II are most likely to occur as the result of secretion by viable mast cells rather than leaching of protease from dead or dying cells as treatments that increase mast cell numbers (parasite infestation) or result in mast cell depletion (irradiation or cyclosporin A treatment) are paralleled by comparable increases or decreases in RMCP-II concentrations. ${ }^{21-23}$ The stimulus for, and mechanisms of control of this basal secretion remain to be elucidated but it may be regulated by locally produced cytokines.

Release of RMCP-II into the blood during systemic anaphylaxis has been correlated with the translocation of Evans blue labelled plasma albumin into the gut lumen ${ }^{56}$ suggesting a relation between RMCP-II and increased epithelial and endothelial permeability. In this study, concentrations of RMCP-II in the vascular perfusate increased extremely rapidly (within 40 seconds) after anaphylactic challenge of primed rats, and reached a plateau rats $(45.9(38 \cdot 6-121 \cdot 2) \mu \mathrm{g} / \mathrm{g}$ wet weight) $(\mathrm{p}<0.01)$. In the second experiment no differimmune (925 (423-1222) $\mu \mathrm{g} / \mathrm{g}$ wet weig and immune control groups (757 (591-1036) $\mu \mathrm{g} / \mathrm{g}$ wet weight). The concentrations of RMCP-II in jejunal tissues were significantly higher, however, in both the immune groups 
within two minutes, which is in keeping with previous in vivo findings by $\mathrm{King}^{24}$ showing an increase at 90 seconds (first sample point) plateauing at six minutes after challenge. These data compare well with the time course of IgE mediated release of mast cell mediators from cultured bone marrow derived mouse and rat mast cells, which plateau roughly five minutes after stimulation. ${ }^{25} 26$ This study also supports the in vivo studies in suggesting that increased endothelial permeability to RMCP-II and other protein molecules occurs almost instantaneously after mast cell degranulation. ${ }^{24}$ While it still remains to be proved that RMCP-II itself can change endothelial permeability, it is known that other mast cell derived mediators including platelet activating factor and leukotrienes can change vascular permeability during anaphylaxis. ${ }^{27} 28$ In particular, histamine is known to cause extremely rapid changes in the permeability of postcapillary venules. ${ }^{29}$

During systemic anaphylaxis in the rat, intestinal epithelium is rapidly shed, $<90$ seconds after challenge, ${ }^{24}$ and disruption of the basement membrane has been seen after intraluminal challenge of ovalbumin sensitised rats $^{30}$ also associated with RMCP-II release. These findings, and in vitro studies suggesting that RMCP-II may catabolise type IV collagen, have led to the conclusion that increased gut epithelial permeability is caused by the disruption of the basement membrane by RMCP-II leading to breaks in the mucosal continuity. ${ }^{31}$ In this ex vivo experiment some epithelial shedding was seen in both control and challenge groups although the lesions were confined to the tips of the villi and did not resemble the extensive lesions seen in vivo. 631 Importantly the lesions in controls were not associated with the anaphylactic release of RMCP-II, nor were the other lesions, including blebbing of the epithelium at the sides of the villi. Such changes have been described, for example, in association with radiation induced damage $^{15}$ and are thought to be associated with mast cell activation. In these experiments, the few lesions seen were possibly the result of handling the intestine during perfusion and fixation as there was no difference between the control and immune challenge intestines. The basement membrane disruption described by Patrick et al $^{30}$ in association with the release of RMCP-II into the gut lumen occurred four hours after intraluminal challenge with antigen. Recent studies suggest that both human mast cell chymase ${ }^{32}$ and RMCP-II ${ }^{33}$ activate metalloproteinases and it is therefore possible that over a longer (chronic) time course the basement membrane is degraded by collagenases activated by RMCP-II. RMCP-II has also been shown to cause an increase in permeability of pulmonary epithelial cell monolayers, which was reversible with time ${ }^{34}$ showing that the cellular structure of the monolayer itself was not damaged. These results are further supported by more recent findings that, after intestinal challenge of sensitised rats with ovalbumin, leakage of plasma macromolecules into the gut lumen occurs without evidence of ultrastructural damage to the gut mucosa. ${ }^{35}$ It is, therefore, possible that at least in the acute anaphylactic response RMCP-II may have a role in changing permeability by acting on the tight junctions rather than the basement membrane.

The ex vivo model is clearly different from in vivo anaphylaxis in that plasma proteins and cells are washed out of the perfused vasculature. During in vivo anaphylaxis, clotting and blood stasis occur in the microvasculature, and, coupled with a drop in blood pressure, these changes probably contribute to anoxia of the intestine, which may be more important in causing cell death and loss of epithelial cells ${ }^{36}$ than specific inflammatory mediators. Under these circumstances of reduced tissue perfusion, however, concentrations of free RMCP-II may be very substantial, reflecting the 2-3 mg RMCP-II stored per gram wet weight of jejunum. ${ }^{18}$ If, as occurs in vitro after IgE mediated activation of rat bone marrow derived mast cells, ${ }^{26} 15-20 \%$ of the stored RMCP-II were released, concentrations of RMCP-II in the interstitial fluid could be as high as $3-6 \mathrm{mg} / \mathrm{ml}$. The proteolytic activity of the chymase might then become more important in causing direct tissue damage. Although a drop in flow rate was seen after antigen challenge during the ex vivo perfusion, the continuous input by the peristaltic pump may ensure that there is sufficient flow of perfusate to effectively wash out released protease from the interstitial spaces thus limiting the concentration of RMCP-II in the interstitial fluid.

The decrease in flow rate seen in the ex vivo system is a practical indicator that a response has occurred, however, the reason for the change has not been established but may be the result of changes in vascular permeability or vascular tone, or both. The finding that flow rate changes were observable in naive rats challenged with worm antigen but not in immune rats challenged with bovine serum albumin suggests that the vascular response was not mediated totally by a specific IgE mechanism and that other factors in the crude worm homogenate could be having a direct effect on the microvasculature. There was a significantly $(p<0.001)$ greater effect, however, in immune rats challenged with worm antigen implying that the release of mediators from specifically sensitised cells was a contributory factor.

Overall, these experiments have provided conclusive evidence that the jejunum is an important source of RMCP-II, secreted at continuous low concentrations even in normal rats and released during anaphylaxis. It is also evident that changes in vascular permeability in the gut occur very rapidly after challenge. Further work is necessary, however, to evaluate how the release of RMCP-II relates temporally to changes in gut epithelial permeability and to show that the permeability change applies to other macromolecules. In this respect the perfusion system provides a useful model for studying the dynamic output of inflammatory mediators from the gut and their relation to permeability changes. The 
study has also challenged the putative role of RMCP-II in causing shedding of intestinal epithelium during anaphylaxis.

This work was supported by a grant from the Wellcome Trust. The authors are grateful to the staff of the Histopathology Laboratory, Department of Veterinary Pathology, R(D)SVS, Veterinary Field Station for their technical assistance.

1 Crowe SE, Perdue MH. Gastrointestinal food hypersensitivity: basic mechanisms of pathophysiology. Gastroenterology 1992; 103: 1075-95.

2 Crowe SE, Perdue MH. Functional abnormalities in the intestine associated with mucosal mast cell activation. Reg Immunol 1992; 4: 113-7.

3 Miller HRP. Immunopathology of gastrointestinal nematode infestation and expulsion. Current Opinion in Gastroenterology 1993; 9: 986-93.

4 Huntley JF, MacKellar A, Newlands GF, Irvine J, Miller HRP. Mapping of the rat mast cell granule proteinases RMCPI and II by enzyme-linked immunosorbent assay and paired immunofluorescence. APMIS 1990; 98: 933-44.

5 Miller HRP, Woodbury RG, Huntley JF, Newlands GFJ Systemic release of mucosal mast cell protease in primed rats challenged with Nippostrongylus brasiliensis. Immunology 1983; 49: 471-9.

6 King SJ, Miller HRP. Anaphylactic release of mucosal mast cell protease and its relationship to gut permeability in Nippostrongylus-primed rats. Immunology 1984; 51: 653-60.

7 Sage H, Woodbury RG, Bornstein P. Structural studies on human type IV collagen. F Biol Chem 1979; 254:

8 Barth EEE, Jarrett WFH, Urquhart GM. Studies on the mechanism of the self cure reaction in rats infected with Nippostrongylus brasiliensis. Immunology 1966; 10 459-64.

9 Miller HRP. Mast cells: their function and heterogeneity. In: Moqbel R, ed. Allergy and immunity to helminths: common mechanisms or divergent pathways. London: Taylor and Francis, 1992: 228-48.

10 Sanderson IR, Walker WA. Uptake and transport of macromolecules by the intestine: possible role in clinical disorders (an update). Gastroenterology 1993; 104: 622-39.

11 Hanson PJ, Parsons DS. The utilisation of glucose and production of lactate by in vitro preparations of rat small intestine: effects of vascular perfusion. $\mathcal{f}$ Physiol 1976 255: 775-95.

12 Pennington AM, Corpe CP, Kellet GL. Rapid regulation of rat jejunal glucose transport by insulin in a luminally and vascularly perfused preparation. 7 Physiol 1994; 478: 187-93.

13 Nawa Y, Miller HRP. Protection against Nippostrongylus brasiliensis by adoptive immunization with immune thoracic duct lymphocytes. Cell Immunol 1978; 37: 51-60.

14 Nawa Y, Miller HRP, Hall E, Jarrett EEE. Adoptive transfer of total and parasite specific IgE responses in rats infected with Nippostrongylus brasiliensis. Immunology 1981; 44: 119-23.

15 MacNaughton WK, Leach KE, Prud'homme-Lalonde L Ho W, Sharkey KA. Ionizing radiation reduces neurally evoked electrolyte transport in rat ileum through a mast cell-dependent mechanism. Gastroenterology 1994; 106: 324-35.

16 Woodbury RG, Neurath H. Purification of an atypical mast cell protease and its levels in developing rats. Biochemistry 1978; 17: 4298-304.

17 Woodbury RG, Gruzenski GM, Lagunoff D. Immunoflurescent localization of a serine protease in rat Immunoflurescent localization of a serine protease in

18 Miller HRP, Huntley JF, Newlands GFJ, Irvine J. Granule chymases and the characterization of mast cell phenotype and function in rat and mouse. In: Schwartz LB, ed Monogr Allergy 27. Neutral protease of mast cells. Basle: Karger, 1990: 1-30.
19 King SJ, Miller HRP, Woodbury RG, Newlands GF. Gut mucosal mast cells in Nippostrongylus-primed rats are the major source of secreted rat mast cell protease II followin systemic anaphylaxis. Eur f Immunol 1986; 16: 151-5.

20 Miller HRP, Huntley JF, Newlands GFJ. Mast cell chymases in helminthosis and hypersensitivity. In: Caughey GH. The biology of mast cell proteases. New York: Marcel Dekker, (in press)

21 Cummins AG, Munro GH, Huntley JF, Miller HRP, Ferguson A. Separate effects of irradiation and of graftversus-host reaction on rat mucosal mast cells. Gut 1989 30: $355-60$.

22 Cummins AG, Munro GH, Miller HRP, Ferguson A Effect of cyclosporin A treatment on the enteropathy of graft-versus-host reaction in the rat: a quantitative study of intestinal morphology, epithelial cell kinetics and mucosal immune activity. Immunol Cell Biol 1989; 67: 153-60.

23 Woodbury RG, Miller HRP, Huntley JF, Newlands GFJ, Palliser AC, Wakelin D. Mucosal mast cells are functionally active during spontaneous expulsion of intestinal nematode infections in rat. Nature $1984 ; 312$ 450-2.

24 King SJ. Hypersensitivity mechanisms and mucus in the immune expulsion of Nippostrongylus brasiliensis from the rat [thesis]. Edinburgh: University of Edinburgh, 1986.

25 Razin E, Mencia-Huerta J-M, Stevens RL, Lewis RA, Liu F-T, Corey EJ, et al. IgE-mediated release of leukotriene $\mathrm{C} 4$, chondroitin sulphate $\mathrm{E}$ proteoglycan, $\beta$-hexosaminidase and histamine from cultured bone marrow-derived mouse mast cells. F Exp Med 1983; 157: marrow-deri

26 MacDonald AJ, Haig DM, Bazin $\mathrm{H}$, McGuigan AC Moqbel R, Miller HRP. IgE-mediated release of rat mast cell protease II, $\beta$-hexosaminidase and leukotriene $C_{4}$ from cultured bone marrow-derived rat mast cells. Immunology 1989; 67: 414-8.

27 Leng W, Kuo CG, Quershi R, Jakschik BA. Role of leukotrienes in vascular changes in the rat mesentery and skin in anaphylaxis. 7 Immunol 1988; 140: 2361-8.

28 Fernadez-Gallardo S, Gijon MA, Garcia C, Furio V, Liu F-T, Crespo MS. The role of platelet-activating factor and peptidoleukotrienes in the vascular changes of rat passive anaphylaxis. Br f Pharmacol 1992; 105: of rat pass

29 Rippe B, Haraldsson B. Transport of macromolecules across microvascular walls: the two pore theory. Physiol Rev 1994; 74: 163-219.

30 Patrick MK, Dunn IJ, Buret A, Miller HRP, Huntley JF, Gibson S, Gall DG. Mast cell protease release and mucosal ultrastructure during intestinal anaphylaxis in the rat. Gastroenterology 1988; 94: 1-9.

31 Miller HRP, King SJ, Gibson S, Huntley JF, Newlands GFJ, Woodbury RG. Intestinal mucosal mast cells in normal and parasitized rats. In: Befus $A D$, Bienstock $J$ Denburg JA, eds. Mast cell differentiation and heterogeneity. New York: Raven Press, 1986: 239-55.

32 Saarinen J, Kalkkinen N, Welgus HG, Kovanen PT. Activation of human interstitial procollagenase through direct cleavage of the Leu (83)- Thr (84) bond by mastcell chymase. F Biol Chem 1994; 269: 18134-40.

33 Suzuki K, Lees M, Newlands GFJ, Nagase H, Woolley DE Activation of precursors for matrix metalloproteinases 1 (interstitial collagenase) and 3 (stromeolysin 1) by rat mast cell proteinases I and II. Biochem $\mathcal{f}$ (in press).

34 Woodbury RG, Le Trong $\mathrm{H}$, Cole $\mathrm{K}$, Neurath $\mathrm{H}$, Miller HRP. Rat mast cell proteases. In: Galli SJ, Austen $\mathrm{KF}$, eds. Mast cell and basophil differentiation and function in health and disease. New York: Raven Press, 1989: 71-9.

35 Persson CGA, Gustafsson B, Erjefalt JS, Sundler F. Mucosal exudation of plasma is a noninjurious intestinal defense mechanism. Allergy 1993; 48: 581-6.

36 Marsh MN. Morphologic expression of immunologicallymediated change and injury within the human smal intestinal mucosa. In: Batt RM, Lawrence TLJ, ed. Function and dysfunction of the small intestine. Liverpool: Liverpool University Press, 1983: 167-98. 